\title{
Nasopalatin Cyst: Diagnosis to Treatment
}

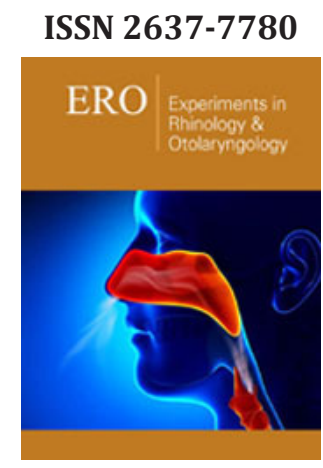

*Corresponding author: Koné FI, Assistant Professor, ENT Head and Neck Surgery, Mali

Submission: 侮June 11, 2019

Published: 䟧June 18, 2019

Volume 3 - Issue 1

How to cite this article: Fatogoma Issa Koné, Cissé N, Dembélé Y, Diarra K, Samaké D, et al. Nasopalatin Cyst: Diagnosis to Treatment. Exp Rhinol Otolaryngol 3(1). ERO.000553.2019.

DOI: 10.31031/ERO.2019.03.000553

Copyright@ Koné FI, This article is distributed under the terms of the Creative Commons Attribution 4.0 International License, which permits unrestricted use and redistribution provided that the original author and source are credited.

\author{
Fatogoma Issa Koné ${ }^{1 *}$, Cissé $\mathbf{N}^{1}$, Dembélé $\mathbf{Y} 1$, Diarra $\mathrm{K}^{1}$, Samaké $\mathrm{D}^{1}$, Tafo $\mathbf{N}^{1}$, \\ Konaté $\mathrm{NF}^{1}$, Soumaoro $\mathrm{S}^{1}$, Guind $\mathrm{B}^{1}$, Kadidiatou $\mathrm{S}^{1}$, Timbo $\mathrm{SK}^{1}$, Kéita $\mathrm{MA}^{1}$ \\ ${ }^{1}$ Department of Head and Neck Surgery, Mali
}

\begin{abstract}
Objectives: We report two cases of nasopalatine cyst by discussing the diagnostic and therapeutic aspect and review the literature.

Case report: There were two cases of nasopalatin cyst aged 20 years and 19 years respectively. We noted a mass filling the upper vestibular in our two patients. Computed tomography showed a fluid cyst located in the nasopalatin duct. Surgery was performed under general anesthesia in the first patient and local anesthesia in the second patient. Anatomopathological examination of the room highlighted a cyst. No operative incident was noted.
\end{abstract}

Conclusion: The nasopalatin cyst is an epithelial, embryonic non-odontogenic tumor of the maxillae. His diagnosis is radiological and histological. The vestibular surgical approach may allow complete excision of the cyst without dental, neurovascular and bucco-nasal fistula lesions.

Keywords: Nasopalatin cyst; Computed tomography; Histology

\section{Introduction}

The nasopalatin canal cyst or incisor canal cyst, commonly known as the nasopalatin cyst (KNP), was first described by Meyer in 1914 [1]. It is an epithelial, non- odontogenic embryonic tumor of the maxillae [1-5]. A WHO classification in 1992 consideres it as a nonodontogenic epithelial cyst [1]. Its incidence is the most common non- odontogenic epithelial cyst and varies between 0.08 at $1.5 \%$ [1]. It is in fact a cyst of embryonic origin: the remains of the non-odontogenic epithelium originating from the maxillofacial buds are incriminated in its genesis [2]. The nasopalatin cyst may be asymptomatic and fortuitously found on a dental panoramic, a rhinosinusic CT or a dentascan or be revealed the gold of super infection by inflammatory signs or palatal and / or nasal fistula with purulent discharge [1,2]. Histologically, it is in the form of a mucous membrane lined with squamous epithelium on the oral surface and a pseudo stratified epithelial lining of the respiratory type on the nasal slope [1-4]. Coexistence with healthy teeth, a source of equivocation by some practitioners, is of therapeutic interest. The treatment is surgical by complete excision of the vestibular and palate [2-4]. We report two cases of nasopalatin cyst by discussing the diagnostic and therapeutic aspect and reviewing the literature.

\section{Case Report}

\section{Case report 1}

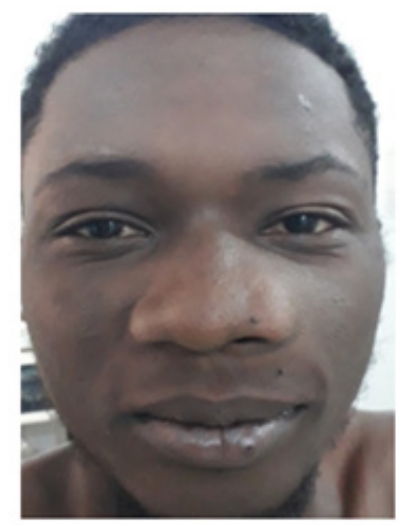

Figure1: Filling of the left nasolabial fold. 


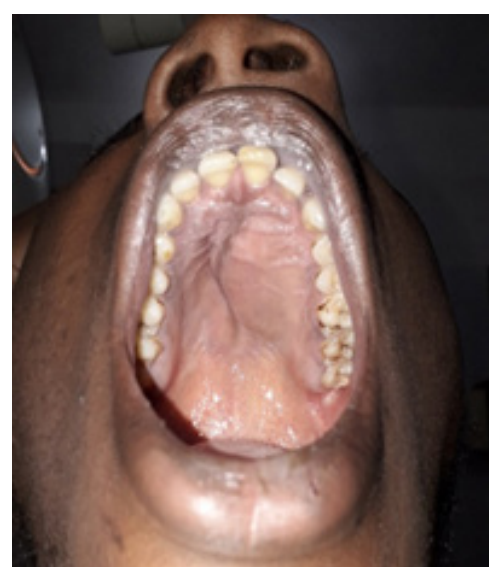

Figure 2: Swelling of the left hemi palace.

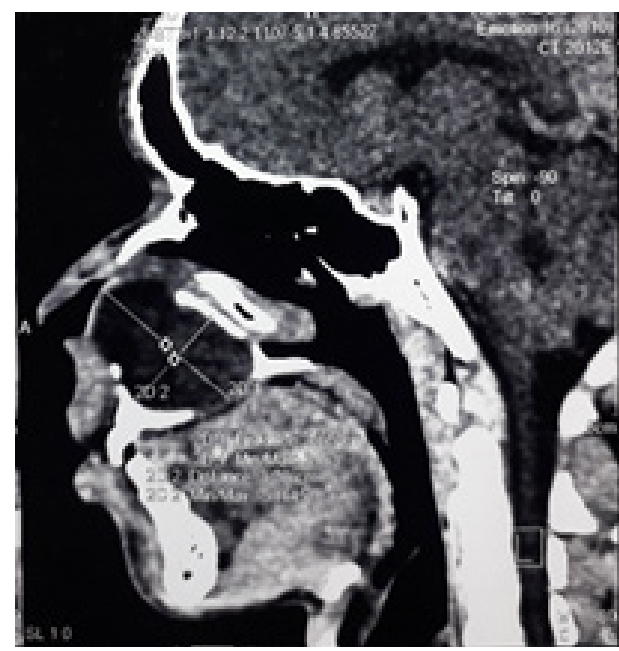

Figure 3: Computed tomography in sagittal section: A cyst with liquid content, measuring $5 \times 3 \mathrm{~cm}$, sitting on the nasopalatin canal.

Patient male of 20 years old, presented a mass under left vestibular (Figure1), a purulent gingival flow compared to the receding upper incisor recurrent for one year. No particular antecedent has been found. The mass filled the upper left vestibule, partially obstructed the left nasal fossa and extended to the hard palate (Figure 2). The palate was ogival, firm and painless without a fistula opening. Computed tomography showed a cyst with fluid content, measuring $5 \times 3 \mathrm{~cm}$, sitting in the nasopalatine canal (Figure 3). Therapy was surgical under general anesthesia; the approach was under vestibular with exposure and complete dissection of the cystic pocket. The histology of the operative specimen found a cyst with no evidence of malignancy. The outcome of the surgery was good.

\section{Case report 2}

Patient male of 19-years-old, presented a bilateral vestibular mass (Figure 4) for four years. No particular antecedent has been found. The mass filled the upper vestibule, partially obstructed the nasal fossae and extended to the hard palate (Figure 5). Deformation of the upper dental arch was noted without rhizalysis. Computed tomography showed a fluid-containing cyst, measuring $6.6 \times 4.6 \mathrm{~cm}$, sitting in the nasopalatin canal (Figure 6). Therapy was surgical under local anesthesia; the approach was sub vestibular with exposure and complete dissection of the cystic pocket (Figure7) The histological study of the operative specimen found a squamous mucosa with conjunctivo-vascular axes. by a squamous epithelium. The outcome of the surgery was good.

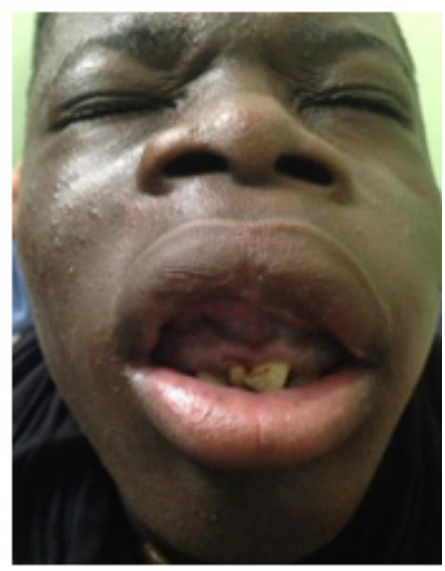

Figure 4: Filling of nasolabial fold and vestibular.

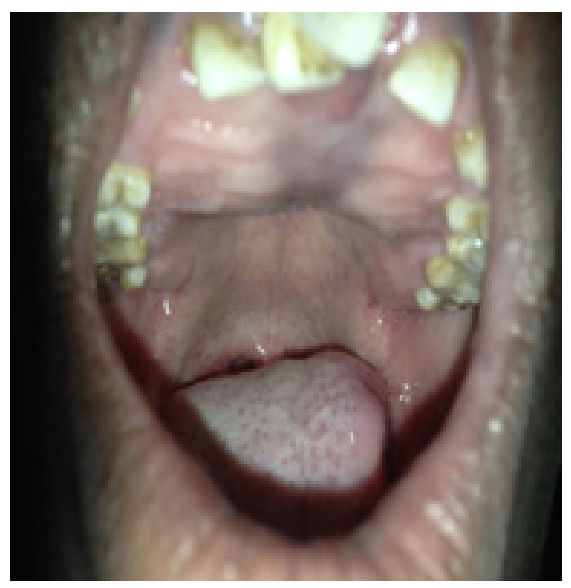

Figure 5: Swelling of the hard palate by the cyst.

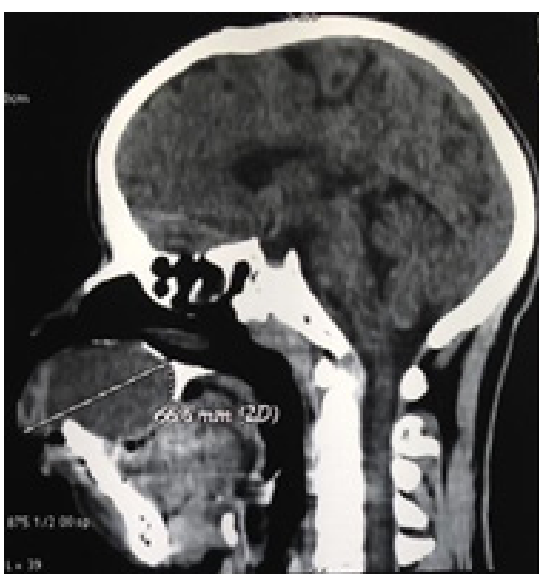

Figure 6: Maxillofacial tomodensitometry in sagittal section highlighting a cyst with fluid content, measuring $6.6 \times 4.6 \mathrm{~cm}$, sitting at the canal level nasopalatin. 


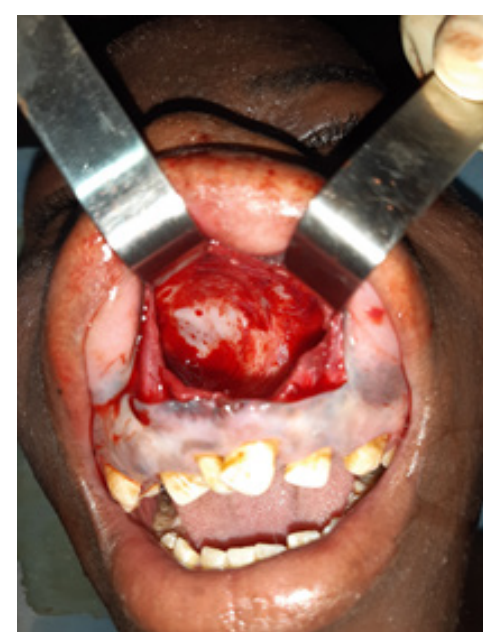

Figure 7: Preoperative view after vestibular excision of nasopalatin cyst.

\section{Discussion}

The formation of the nasopalatin canal is made from the fusion of the primary palate and secondary palate to the $12^{\text {th }}$ week of embryonic life [1-3]. In post-natal the final diameter of the nasopalatine canal is about 3 to $10,19+3.24 \mathrm{~mm}$ anteroposterior and that $4,79+1,33 \mathrm{~mm}$; dilation of the canal beyond these dimensions should make one suspect cystic formation $[2,3,6]$. It is the most common non-ontogenic cyst group with an incidence of about 0.7 to $3.6 \%[2]$.

The etiology of the nasopalatin cyst is unknown but several hypotheses have been put forward:

A. The most commonly accepted is the development of the cyst from an embryonic remnant of cells of the antero- inferior part of the lacrimal duct $[1-3,5,6]$.

B. The second mechanism, this cyst would result from embryonic epithelial remains unincorporated during the fusion of the lateral nasal bud and the nasal part of the maxillary process.

C. Anterior trauma, poorly fitting prostheses, local infection, genetics, and ethnicity are other factors suggested to explain the development of nasopalatine cysts $[3,7]$. Implantation of dental implants would worsen the rapid growth of asymptomatic cysts, which could compromise the integrity of nearby dental implants [3].

The embryonic hypothesis may be suspected with both patients. The clinical spectrum is in the form of an asymptomatic and painless cyst. The cysts of the nasopalatine canal are asymptomatic in 30 to $50 \%$ and fortuitously discovered on a dental panoramic radiography, a rhino-sinus computed tomography or a dentascan [1]. It is reported that this delay is 30 to 40 months [2]. The consultation periods were 12 months for the first case and 48 months for the second case. The signs become evident in superinfection and manifest as palatal pain, painful vestibular mass, palatal and / or nasal fistula with purulent discharge [1-3,6]. The clinical spectrum of our patients presented to describe a mass well circumscribed, located below the nostril threshold, at the level of the canine region in our first case. This mass was painless, of soft, fluctuating consistency, of slow growth. The physical examination shows a deformation of the floor of the nasal fossa associated with nasal obstruction and obliteration of the nasolabial fold and palpation. This symptomatology deviates rich in cases of large cyst, can distort the architecture of the teeth, destroy the surrounding bone and invade the floor of the nasal cavity with or without nasal obstruction and obliteration of the nasolabial fold [2]. This does not seem to be shared by some authors because of the lack of correlation between the size of the cyst and the importance of the symptoms on the one hand and the age of the patient on the other hand [7].

Imaging in addition to the clinic whose reference examination is CT allows us to visualize well circumscribed mass, away from the dental roots, extra periosteum, with a thin wall and a fluid content. Adjacent bone structures (absence of bone lysis with sometimes a concave aspect of the vestibular table external maxilla) [1-6]. Magnetic resonance imaging confirms the fluid nature of the mass but is less efficient for exploration of adjacent bone [1-6]. As for the dental panoramic associated with an occlusal picture with or without opacification of the cyst, it is no longer practiced [1-6]. In our case the CT has returned a hypodensity circumscribed about $5 \times 3 \mathrm{~cm}$ for the former and approximately $6.6 \times 4,6 \mathrm{~cm}$ for the second sitting on the route of the nasopalatine canal without adjacent bone resorption with partial resorption of the hard palate. The reference treatment is surgical. It is enucleation under general or local anesthetic by the vestibular and palatal route [1-6]. The surveillance concerns asymptomatic cysts of $6 \mathrm{~mm}$ and less [1]. The first case was operated under general anesthesia and the second under local anesthesia. Sequelae can be reconstructed by palate graft to close naso-oral communication [6]. Recurrences are rare, about 0 at $11 \%$. They are due to incomplete excision $[1,2,6]$. We did not notice any cases of recurrence due to complete excision. Vestibular endoscopic surgery reported by JW Kang [4]. less invasive with a lower recurrence rate. The operative incident is nervous and hemorrhagic with regard to the large nervous trunks and numerous vessels in the hull $[1-3,5]$. No operative incident was noted.

\section{Conclusion}

The nasopalatine cyst is an epithelial, non-odontogenic embryonic tumor of the maxillae. His diagnosis is radiological and histological. The symptomatology is a function of the volume of the cyst. L Management is surgical and surgical facial abord allows complete excision of the cyst without dental lesion, neurovascular or oral nasal fistula.

\section{References}

1. Righini CA, Boubagra K, Bettega G, Verougstreate G, Reyt E (2004) Nasopalatine canal cyst: 4 cases and a review of the literature. Ann Otolaryngol Chir Cervicofac 121(2): 115-119.

2. Slama L Ben, Zoghbanic A, Hidayaa S (2009) Nasopalatine duct cyst. Rev Stomatol Chir Maxillofac 110: 284-286.

3. Lake S, Iwanaga J, Kikuta S, Oskouian RJ, Loukas M, et al. (2018) The incisive canal: A Comprehensive Review. Cureus 10(7): e3069. 
4. Kang JW, Kim HJ, Nam W, Kim CH (2014) Endoscopic endonasal marsupialization of nasopalatine duct cyst. J Craniofac Surg 25(2): e155-e156.

5. Jones RS, Dillon J (2016) Nonodontogenic cysts of the jaws and treatment in the pediatric population. Oral Maxillofac Surg Clin North Am 28: 31 44.
6. Sankar D, Muthusubramanian V, Nathan JA, Nutalapati RS, Jose YM, et al. (2016) Aggressive nasopalatine duct cyst with complete destruction of palatine bone. J Pharm Bioallied Sci 8(1): S185-S188.

7. Swanson KS, Kaugars GE, Gunsolley JC (1991) Nasopalatine duct cyst: An analysis of 334 cases. J Oral Maxillofac Surg 49(3): 268-271. 